\title{
Practice guidelines in Finland: availability and quality
}

\author{
Helena Varonen, Marjukka Mäkelä
}

\begin{abstract}
Objective-To describe the quantity, quality, and availability of practice guidelines currently used in Finland.

Design-Cross sectional survey.

Methods-Guidelines from 1989 to 1995 were collected through a database search, through hand searches of the two Finnish general medical journals, and through an inquiry into hospitals, health centres, and medical societies. The content and source of evidence for guidelines was assessed.

Results-719 practice guidelines were found. 578 guidelines $(80 \%)$ were retrieved by the inquiry, the database search identified $27(4 \%)$ and hand searches $106(15 \%)$. There were 150 guidelines $(21 \%)$ developed nationally, $120(17 \%)$ regionally, and $449(62 \%)$ locally. The structure and quality of evidence supporting the guidelines was variable and only two guidelines were based on meta-analysis. The references were significantly more often $(P<0.001)$ documented in the national guidelines $(n=129,86 \%)$ than in the regional or local guidelines $(n=65,11 \%)$.

Conclusions-There are many ways of disseminating guidelines and it may be difficult for end users to find the appropriate guidelines. Sources of evidence were seldom documented in the regional and local guidelines and even some national guidelines lacked all references. More attention should be paid to documenting the level of evidence, structuring the guidelines, and creating optimal strategies for development and dissemination of guidelines. (Quality in Health Care 1997;6:75-79)
\end{abstract}

\section{Keywords: practice guidelines; quality assessment}

Stakes, National Research and Development Centre for Welfare and Health,

Department of Services and Quality, PL 220, 00531 Helsinki, Finland

Helena Varonen, research officer

Marjukka Mäkelä, head of research and development

Correspondence to: Dr Helena Varonen, Stakes, Department of Services and Quality, PL 220, 00531 Helsinki, Finland.

Accepted for publication 6 January 1996
Much medical information can be summed up in practice guidelines in a short and readily usable format. Accepting and using evidence based practice guidelines can help toward a more effective use of limited healthcare resources. ${ }^{1}$ Guidelines may standardise and improve healthcare delivery and help healthcare staff in assessing the quality of their own clinical practice. Guidelines should professionals and patients in decision making. Practice guidelines have been shown to improve clinical practices when developed, disseminated, and introduced appropriately. ${ }^{23}$ Protocols on development of guidelines are proliferating, ${ }^{45}$ but little is known of the quality and amount of evidence underpinning provide valid recommendations to aid guidelines actually used by professionals. In the United States, the content and style of 24 consensus statements has been soundly scrutinised, ${ }^{6}$ but to our knowledge the whole range of clinical practice guidelines has not been studied in any country.

The aim of our study was to collect and evaluate all the guidelines currently available in Finland. The Finnish Medical Society Duodecim has started a systematic development of practice guidelines and our survey was designed to collect basic information for this initiative. We wanted to find out to what extent the current guidelines are based on evidence and what we could learn about their quality and availability to plan a more systematic process for developing guidelines. In this article we describe the content, quality, and scientific basis of the clinical practice guidelines currently available in Finland.

\section{Material and methods}

SEARCH STRATEGY

Our pilot study showed that practice guidelines are not easy to find: only a few were identified in a literature search. Because the means of publication and dissemination of guidelines were variable, we combined several search strategies: a database search, hand searches, and a survey of guideline users and developers.

We ran the literature search in June 1995 in the Medic database that covers Finnish healthcare literature. The search terms were guidelines, practice guidelines, clinical practice, instructions for treatment, treatment policy, reference standards, and the equivalents of these words in Finnish. Hand searches were done on the volumes of the two Finnish general medical journals, Duodecim and Suomen Lääkärilehti, from 1989 onwards. We also searched the publication series of the Ministry of Social Affairs and Health, the National Board of Health, and the National Research and Development Centre for Welfare and Health and our personal files.

SURVEY

Knowing that hospitals have many unpublished guidelines of their own, we posted an inquiry to all central $(n=16)$ and university hospitals $(n=5)$ in Spring 1995 asking them to send us copies of the guidelines that were actively used by them. The letters were addressed to the chief clinical officers. We did not define practice guidelines in the inquiry; instead we sent a structure for an ideal guideline and stated that we were not collecting instructions intended for patients. 
Those who had not answered were reminded once by telephone. In June 1995 the inquiry was extended to district $(n=30)$ and psychiatric hospitals $(n=29)$, the 13 largest health centres, and to medical societies or patients' associations known or thought to have developed practice guidelines $(n=38)$. These sources were not further contacted.

INCLUSION AND EXCLUSION CRITERIA

Practice guidelines were defined as "statements to assist practitioner and patient decisions about appropriate health care for specific clinical circumstances". ${ }^{7}$ Our inclusion criteria covered all guidelines published in Finnish in 1989 or later. Guidelines for very rare diseases were excluded.

Being interested in individual guidelines, we excluded medical textbooks and the physician's desk reference and database. ${ }^{8}$ Medical textbooks contain many and sometimes also up to date guidelines for health care, but the clarity and practicability of these guidelines is variable and often they represent the opinion of only one specialist. The Physician's Desk Reference and Database is a collection of over 1100 guidelines for general practitioners published by the Finnish Medical Society Duodecim and is available in Finnish on CD-ROM, diskette, and in textbook formats. ${ }^{9}$ The guidelines in the database are produced systematically to cover all specialties. They are peer reviewed and updated regularly. Their scientific basis varies from expert opinions to extensive literature reviews.

DATA COLLECTION AND STATISTICAL ANALYSIS The content and source of evidence for the guidelines were rated by one primary investigator (HV). We used a data collection form (table 1) and formed a Paradox database of the collected guidelines. The type of literature review (non-systematic or systematic) was used as an indicator of quality. Our variables covered methods for producing guideline, topic areas, and structural content. Unclear classifications were assessed by $\mathrm{MM}$ and the rating was done by consensus. Significance was measured with $\chi^{2}$ statistics or Fisher's exact test in Epistat software.

We did not attempt to perform an analysis of the medical content. For our purposes the existing appraisal instruments were not practical. If a guideline was retrieved from several sources, we registered the easiest method of retrieval from the end user's point of view for example, firstly the database searches, then the hand searches, and lastly the inquiry. If a national guideline was modified for regional or local use, we treated both as separate guidelines.

\section{Results}

COLLECTION OF GUIDELINES

Altogether 719 Finnish practice guidelines were retrieved. The database search yielded 84 references of which 27 met our criteria. In the hand searches we found 106 guidelines or other comparable articles. Most of the guidelines were traced through the inquiry.
Table 1 Guidelines data collection form

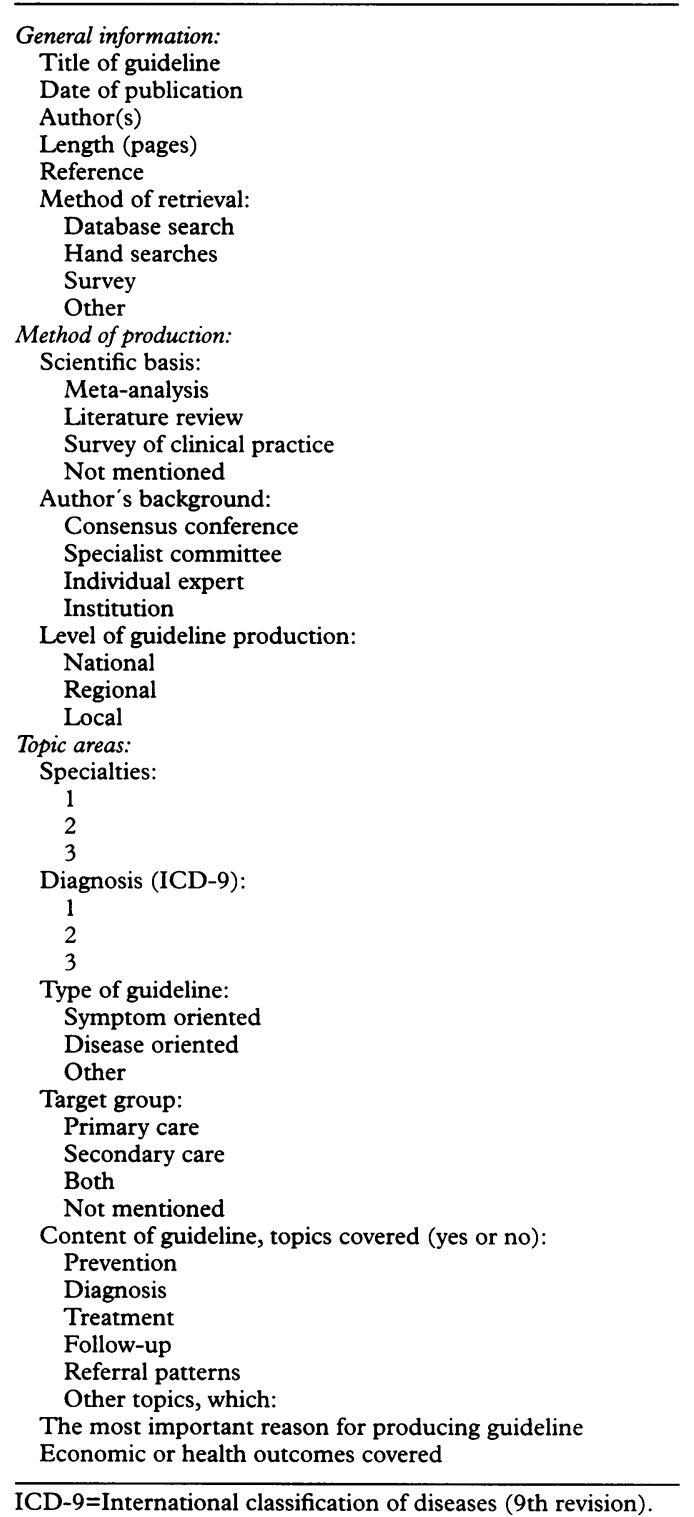

Sixty seven respondents sent us altogether 673 guidelines. Also, eight guidelines were found in our personal files.

The letters accompanying guidelines indicated that the concept of practice guidelines was unfamiliar and was interpreted in many ways. As well as guidelines we received other material such as patient information leaflets, nursing instructions, and administrative statements. We excluded 95 items, among them 32 instructions to patients and 14 guidelines published before 1989 .

All the university hospitals and all but one of 16 central hospitals responded to the inquiry. Four of the 30 district hospitals, one of the 13 largest health centres, and 11 societies or associations out of 38 answered. We did not get any feedback from the psychiatric hospitals. Some guidelines were sent to us from several different sources.

DEVELOPMENT OF GUIDELINES

Guidelines had been developed at national, regional, and local levels. There were 150 national guidelines (21\%) developed by consensus statement conferences, expert committees for specific health problems, medical 
Table 2 Guidelines according to specialty

\begin{tabular}{lc}
\hline & $n(\%)$ \\
\hline Surgery & $212(29)$ \\
Internal medicine & $124(17)$ \\
Gynaecology and obstetrics & $101(14)$ \\
Paediatrics & $90(13)$ \\
Neurology & $35(5)$ \\
Oncology & $23(3)$ \\
Emergency care and anaesthesiology & $20(3)$ \\
Lung diseases & $19(3)$ \\
Ophthalmology & $18(3)$ \\
Psychiatry & $14(2)$ \\
Others & $63(9)$ \\
Total & $719(100)$ \\
\hline
\end{tabular}

associations and organisations, and certain individual experts. The production of some national guidelines had been initiated and funded by policymakers such as the Ministry of Social Affairs and Health.

We received 120 guidelines $(17 \%)$ intended for regional use. Finland is divided into 22 central hospital districts. The central hospitals are responsible for coordinating certain healthcare activities in their region and often distribute written advice to support the coordination. Some hospitals had generated regional modifications of national guidelines. Several versions of regional modifications of the national guideline on diabetes and pregnancy developed by the Finnish Diabetes Association were obtained.

Most of the guidelines ( $n=449,62 \%$ ) were developed for local purposes, usually by hospitals. Some of them were used in other hospitals as well. The practice guideline collections of the university hospitals were the largest single source of material. The guidebook for emergency care produced by and for the Helsinki University Hospital had a wide circulation; it is used all over Finland. Central hospital guidelines for paediatrics were also often used in other hospitals, even outside the region for which they were intended.

CONTENT AND QUALITY OF GUIDELINES

Of the guidelines $73 \%$ pertained to the four largest specialties (table 2). Altogether we received guidelines from 41 different specialties. Twenty five guidelines $(3 \%)$ were written for primary care, 329 (46\%) for secondary care, and $365(51 \%)$ were written for both levels. The length of guidelines varied from less than one page to more than two hundred pages: $73 \%$ were less than five pages in length and $5 \%$ were more than 21 pages.

The scientific bases of practice guidelines varied greatly (table 3 ) and the processes of development were seldom described. Of the guidelines $194(27 \%)$ had references. Two

Table 3 Scientific basis of guidelines

\begin{tabular}{lllll}
\hline & $\begin{array}{l}\text { National } \\
n(\%)\end{array}$ & $\begin{array}{l}\text { Regional } \\
n(\%)\end{array}$ & $\begin{array}{l}\text { Local } \\
n(\%)\end{array}$ & $\begin{array}{l}\text { All } \\
n(\%)\end{array}$ \\
\hline Meta-analysis & $2(1)$ & $0(0)$ & $0(0)$ & $2(0.3)$ \\
Literature review & $123(82)$ & $22(18)$ & $42(9)$ & $187(26)$ \\
Survey of clinical practice & $4(3)$ & $0(0)$ & $1(0.2)$ & $5(0.7)$ \\
Not mentioned & $21(14)$ & $98(82)$ & $406(90)$ & $525(73)$ \\
Total & $150(100)$ & $120(100)$ & $449(100)$ & $719(100)$ \\
\hline
\end{tabular}

^ Also contained a literature review.
Table 4 Content of guidelines

\begin{tabular}{lr}
\hline & $n(\%)$ \\
\hline Treatment & $668(93)$ \\
Diagnosis & $570(79)$ \\
Follow up & $324(45)$ \\
Referral patterns & $180(25)$ \\
Prevention & $98(13)$ \\
Other topics & $108(15)$ \\
\hline
\end{tabular}

guidelines were based on meta-analysis: the guidelines on the prevention of coronary disease ${ }^{10}$ and the recent Finnish guidelines for screening in maternity care, ${ }^{11}$ which has been checked against the Cochrane database on pregnancy and childbirth. ${ }^{12}$

References were given for 129 national guidelines (86\%) (table 3) but the source of evidence was mentioned in only 22 regional $(18 \%)$ and 43 local guidelines (9\%). The national guidelines had references significantly more often than the local and regional ones (test for trend, $\chi^{2}=297, P<0.001$ ). Most of the guidelines discussed treatment and diagnostics. Prevention and follow up were seen less often (table 4). Some guidelines covered screening, goals of treatment, and educational topics.

REASONS FOR DEVELOPMENT OF GUIDELINES We found a statement of the reason for developing the guidelines in $110(15 \%)$ cases. The most typical reason mentioned $(23 \%)$ was to solve an important public health problem. There are detailed guidelines - for example, on the treatment of hypertension, diabetes, coronary disease, stroke, and common forms of cancer. A recent change in clinical practice - for example, the methods for diagnosing allergies - was another typical reason (19\%) for development of guidelines. Other reasons included variations in clinical practices $(15 \%)$ and quality problems $(8 \%)$ in patient care such as delayed referrals to specialists.

\section{OUTCOMES IN GUIDELINES}

We attempted to detect statements of possible economic or health implications of the guidelines; we searched for comments on health outcomes for both individual people and populations. Only 22 guidelines (3\%) discussed health outcomes or economic implications, usually at a very general level for example, "This guideline promotes more cost effective care than the former practice". A few guidelines compared the effects of different treatments on costs or on patients' quality of life.

\section{Discussion}

Although our survey retrieved many guidelines covering most specialties, our retrieval of guidelines was probably far from complete. The channels for publication varied and literature searches were ineffective in tracking down the guidelines. For an average user finding the appropriate guidelines may require too much time and effort. One explanation for ineffective database searches is inadequate indexing, as "practice guidelines" has been a search term 
for only a few years. Searches with disease based subject terms might have produced more references. Without the activity and cooperation of the survey respondents we would have found few guidelines.

Most of the guidelines were sent from secondary care institutions. These guidelines were mostly produced in central hospitals for local or regional use and seldom had references. Four major specialties were well represented, but few guidelines were available from psychiatry. We collected only 14 guidelines concerning this large speciality (2\% of all); some were sent from central hospital psychiatric clinics and the rest were found through literature searches. The organisation of psychiatric health care is separate from that of the somatic hospitals. The contacts between psychiatry and other care providers have also been limited due to regulations concerning confidentiality. Perhaps guidelines have not been considered necessary in self sufficient fields of medicine.

The response from primary care units was scarce. In primary care since 1989 the Physician's Desk Reference and Database has replaced the need to produce individual guidelines to a large extent. The electronic version of the physician's desk reference and database has more than 600 regular subscribers, and 12000 books have been sold since 1992 . As there are altogether 17000 physicians in Finland, the distribution can be considered extensive (Ilkka Kunnamo, personal information). The editors are currently appending explicit statements on the strength of evidence behind the guidelines in that database.

The structure, outline, and length of guidelines varied considerably. Many different names for guidelines were used, and the concept seemed to remain vague for many professionals. Clarifying the concepts and using a common structure in guidelines would make them more usable and readable.

The literature review methods used to find the information for guidelines were not usually discussed in the guidelines themselves. Only two guidelines mentioned used meta-analyses among their sources of information. Of the guidelines $73 \%$ gave no references at all; most of these guidelines were regional or local. Even some recent national guidelines on major diseases lacked all references. Most Finnish guidelines thus seem to be based on opinions rather than evidence. Methods for representing the amount of evidence have improved, ${ }^{13}$ and using them would help the clinician to evaluate the strength of guidelines. Ideally, guidelines can show the level or lack of evidence behind each of the recommendations given.

In a recent study in the United Kingdom $64 \%$ of clinicians considered current guidelines poorly developed and $49 \%$ considered them impractical. ${ }^{14}$ Practice guidelines are best adopted if the users have participated in their development, ${ }^{15}$ but then they may lack the quality of national guidelines. ${ }^{16}$ The many regional and local guidelines we received and the few references we found in them support this view. At a local level the expertise is seldom sufficiently broad, and personal opinions may affect the conclusions. Coordinating the development of guidelines has been recommended to improve their quality and to make them more usable to clinicians. $^{317}$

Finnish guidelines seldom included outcome measures or practice variables, and few guidelines connected recommendations or outcomes with costs. A typical example of outcome evaluation in a guideline was introducing quality of life as one of the outcomes in the treatment of prostatic hyperplasia. Practice variables were targeted at individual patients only - for example, testing blood sugar level targets for diabetic patients. Population oriented outcome measures - for example, percentages of diabetic patients in good metabolic control - were not suggested. Guidelines could be written to support cost consciousness and the use of outcome measures.

This survey highlighted issues on the availability and quality of current guidelines and provided useful information for the Finnish guideline development process. The original concept was to examine the possibility of developing a database of available Finnish practice guidelines and disseminating it to healthcare professionals. This idea was rejected because the current guidelines were not sufficiently evidence based or practical to use due to variability in structure. Instead, Duodecim now coordinates the development of national guidelines with expert groups. These groups use a common basic structure and indicate the level of evidence systematically.

\section{Conclusions}

The varying strategies of dissemination made guidelines difficult to find. Seeking answers to clinical questions from the guidelines may be tedious, as the content and length of guidelines varied considerably, and the strength of recommendations remained obscure. Only a quarter of Finnish guidelines included references, and especially for regional and local guidelines the amount of evidence was low. Current guidelines rarely considered health outcomes or costs. More attention should be paid to systematic development and effective dissemination of guidelines. This survey confirmed the need for establishing a national guideline development process.

1 Sackett DL, Rosenberg WMC. On the need for evidencebased medicine. Health Economics 1995;4:249-54.

2 Grimshaw J, Russell I. Effect of clinical guidelines on medical practice: a systematic review of rigorous evaluations. cal practice: a systematic

3 Lomas J, Anderson GM, Domnick-Pierre K, Vayda E, Enkin MW, Hannah WJ. Do practice guidelines guide Enkin MW, Hannah WJ. Do practice guid

4 Eccles M, Clapp Z, Grimshaw J, Adams PC, Higgins B, Purves I, et al. North of England evidence based guidelines development project: methods of guideline development. BMF 1996;312:760-2

5 Hayward RSA, Wilson MC, Tunis SR, Bass EB, Rubin HR, Haynes B. More Informative abstracts of articles describing clinical practice guidelines. Ann Intern Med 1993; 118:731-7.

6 Kahan JP, Kanouse DE, Winkler JD. Content analysis of 24 consensus statements. In: Kanouse DE, Winkler JD, Kosecoff J, Berry SH, Carter GM, Kahan JP, et al, eds. Changing medical practice through technology assessment. Michigan: Health Administration Press, 1989.

7 Institute of Medicine. Guidelines for clinical practice: from development to use. Washington, DC: National Academic Press, 1992. 
8 Kunnamo I, et al, ed. Yleislääkärin käsikirja ja tietokanta 1/1996. (Physician's desk reference and database). Helsinki: Kustannus Oy Duodecim, 1996. (CD-ROM, In Finnish.)

9 Jousimaa J, Kunnamo I. PDRD - computer-based primary care decision support system. Medical informatics 1993; 18:103-12.

10 Hämäläinen H. Sepelvaltimotaudin sekundaaripreventio ja kuntoutus (Secondary prevention and rehabilitation in coronary disease). Helsinki: Suomen sydäntautilitto ry, coronary disease).

11 Seulontatutkimukset ja yhteistyö äitiyshuollossa. Stakes, Oppaita 27. (Screening and collaboration in maternity care). Jyväskylä: Gummerus Kirjapaino Oy, 1995.(In Finnish.)

12 Cochrane database of systematic reviews. Pregnancy and childbirth module (CCPC). Oxford: Update software, 1994. (Disk issue 2.)
13 Guyatt GH, Sackett DL, Cinclair JC, Hayward R, Cook DJ, Cook RJ, et al. User's guide to the medical literature IX. A method for grading health care recommendations. $\mathfrak{F} A M A$ 1995;274:1800-4.

14 Mansfield CD. Attitudes and behaviours towards clinical guidelines: the clinicians' perspective. Quality in Health guidelines: the clinia
Care 1995;4:250-5.

15 Grimshaw J, Russell II. Achieving health gain through clinical guidelines. II: Ensuring guidelines change medical practice. Quality in Health Care 1994;3:45-52.

16 Grimshaw J, Russell I. Achieving health gain through clinical guidelines. I: Developing scientifically valid guidelines. Quality in Health Care 1993;2:243-8.

17 Oxman AD. Coordination of guidelines development. Can Med Assoc f 1993;148:1285-8. 